\title{
Amyloid Plaque Imaging from IMPY/SPECT to AV-45/PET
}

\author{
Mei-Ping Kung ${ }^{1,2}$, PhD; Chi-Chang Weng ${ }^{3}$, MSc; Kun-Ju Lin ${ }^{1,4}, \mathrm{MD}, \mathrm{PhD}$; \\ Ing-Tsung Hsiao', ${ }^{1}$ PhD; Tzu-Chen Yen ${ }^{4}, \mathrm{MD}, \mathrm{PhD}$; Shiaw-Pyng Wey ${ }^{1}, \mathrm{PhD}$
}

The formation and deposition of $\beta$-amyloid (A $\beta$ ) plaques are the earliest pathological changes in Alzheimer's disease (AD). Molecular imaging of $\mathrm{A} \beta$ plaques could serve as a surrogate marker in early diagnosis and neuropathogenesis studies of AD. Several radionuclide labeled ligands have recently been developed for noninvasive visualization of $A \beta$ plaques in the brains of AD patients using single photon emission computed tomography or positron emission tomography (PET). There has been rapid progress in the field of imaging for plaque pathology. AV-45 was the first plaque imaging agent to enter multi-center, investigational new drug clinical trials in the US, and has now been studied in dozens of trials with more than 1,000 subjects ranging from cognitively normal individuals to those with AD dementia. "Imaging to autopsy" phase III studies further

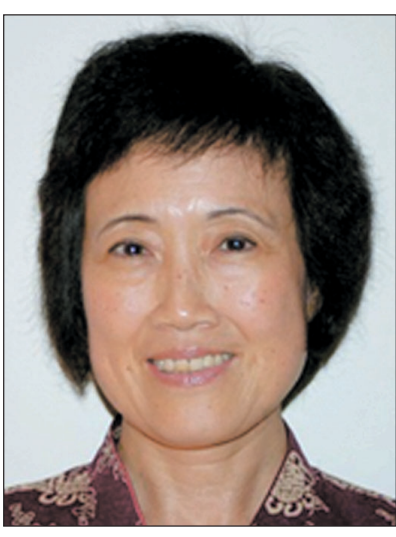

Prof. Mei-Ping Kung confirmed and validated the specific imaging signal correlated to the plaque burden in living subjects. With these promising and confirmed characteristics of AV-45, the Alzheimer's Disease Neuroimaging Initiative (ADNI) under common consensus decided on AV-45 as the emerging standard PET imaging agent for evaluating the progression of plaque pathology in patients with $\mathrm{AD}$ or mild cognition impairment, and even healthy controls. With the wide availability of AV-45 for plaque imaging, the ultimate goal of the ADNI is global clinical trials for disease detection and progression. This review presents recent experience with $A \beta-$ targeting radiotracers at Chang Gung University and Chang Gung Memorial Hospital. (Chang Gung Med J 2012;35:211-8)

Key words: $\beta$-amyloid plaques, Alzheimer's disease, AV-45, AV-138, IMPY

A lzheimer's disease (AD) is a brain disorder resulting in progressive memory loss and other cognitive loss. One of the pathological landmarks found postmortem in the brains of patients is an abundance of senile plaques containing $\beta$-amyloid $(\mathrm{A} \beta)$ peptides. ${ }^{(1,2)}$ While the exact mechanisms underlying the pathology of $\mathrm{AD}$ are not fully understood, reducing deposition of amyloid plaques is believed to be potentially useful to patients. ${ }^{(3,4)}$ Currently, inhibition of $\beta$ - and $\gamma$-secretases responsible for $A \beta$ formation and $A \beta$ immunization to reduce $A \beta$ plaques have been proposed as potential treatments for $A D .{ }^{(5,6)}$ The pivotal role of $A \beta$ aggregates in $A D$ thus provides a strong impetus to search for specific $A \beta$ aggregate-binding agents to target this devastating disease. ${ }^{(2)}$ When labeled with appropriate radioiso-

\footnotetext{
From the ${ }^{1}$ Healthy Aging Research Center and Department of Medical Imaging and Radiological Sciences, College of Medicine, Chang Gung University, Taoyuan, Taiwan; ${ }^{2}$ Department of Radiology, University of Pennsylvania, Pennsylvania, Philadelphia, U.S.A.; ${ }^{3}$ Department of Biomedical Engineering and Environmental Sciences, National Tsing Hua University, Hsinchu, Taiwan; ${ }^{4}$ Molecular Imaging Center, Department of Nuclear Medicine, Chang Gung Memorial Hospital at Linkou, Chang Gung University College of Medicine, Taoyuan, Taiwan.

Received: Jan. 14, 2011; Accepted: Nov. 30, 2011

Correspondence to: Prof. Mei-Ping Kung, Department of Radiology, University of Pennsylvania, PA, U.S.A. 1 Donner, Philadelphia, PA 19104, U.S.A. Tel: 001-484-2708175; E-mail: kungmp@gmail.com
} 
topes, these molecular imaging agents might play important roles serving as in vivo diagnostic tools to detect plaque pathology and monitor the progression of $\mathrm{A} \beta$ aggregates in the brain. Advances in in vivo detection of $\beta$-amyloid formation and aggregation could further facilitate drug development for the disease by providing critical information on plaque burden in the living brain.

\section{IMPY Study}

Among dozens of radioiodinated ligands developed and reported, IMPY [6-iodo-2-(49-dimethylamino-)phenyl-imidazo[1,2- $\alpha$ ]pyridine] (Fig. 1) labeled with ${ }^{125} \mathrm{I}$ or ${ }^{123} \mathrm{I}$ showed the most desirable in vitro and in vivo characteristics to target amyloid plaques. ${ }^{(7,8)}$ Binding studies of $\left[{ }^{125} \mathrm{I}\right] \mathrm{IMPY}$ to the $\mathrm{A} \beta$ plaque-like structures in doubly transgenic mice (PSAPP) were fully evaluated. ${ }^{(9)}$ The feasibility of using [ ${ }^{123}$ I] IMPY in conjunction with micro single photon emission computed tomography (microSPECT) imaging to detect $A \beta$ plaque-like structures in the living brain of PSAPP mice was attempted. However, results of the microSPECT imaging studies were not very encouraging (unpublished result). Several studies further indicated that there is no good, appropriate animal model with plaques resembling those in human brains. ${ }^{(10,11)}$ Subsequent clinical studies of $\left[{ }^{123}\right.$ I]IMPY in healthy subjects and AD patients showed a distribution pattern which was not similar to that of [N-methyl-1-

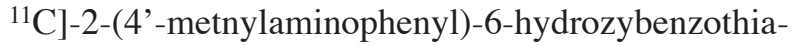
zole ([ $\left.\left.{ }^{11} \mathrm{C}\right] \mathrm{PIB}\right)$, a well characterized and studied PET tracer for plaques, but there was a more perfusion-like pattern, even with a higher accumulation in AD brains compared with age-matched controls (unpublished data). Moreover, the signal-to-noise ratio for plaque labeling of $\left[{ }^{123} \mathrm{I}\right] \mathrm{IMPY}$ was not as robust as that of PIB (PIB showed a $\mathrm{S} / \mathrm{N}$ ratio of

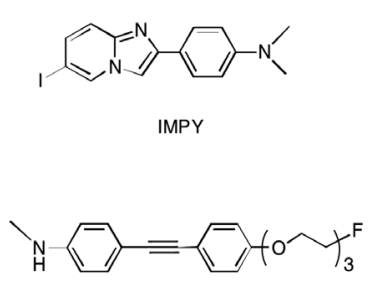

AV-138
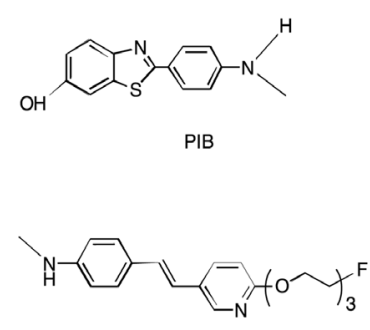

AV-45
Fig. 1 Structures of PIB, IMPY, AV-138 and AV-45. about 2.5 while IMPY displayed a ratio of 1.8 to 2.0 , between 30-50 min after intravenous injection). Because of the fast brain and plasma clearance of [ ${ }^{123}$ I]IMPY observed in AD as well as in healthy subjects, it was believed that the in vivo metabolism/instability of [ $\left.{ }^{123} \mathrm{I}\right] \mathrm{IMPY}$ may ultimately lead to a decreased signal. Taken together, $\left[{ }^{123} \mathrm{I}\right] \mathrm{IMPY}$ did not meet the criteria of a potential plaque imaging agent.

Despite the disappointing results observed for in vivo SPECT imaging with [ ${ }^{123}$ I]IMPY, the ${ }^{125 I}$ labeled tracer [ $\left.{ }^{125} \mathrm{I}\right] \mathrm{IMPY}$ became the most desirable radiotracer for in vitro characterization of plaque binding. High affinity (in $\mathrm{nM}$ range) and high capacity [ $\left.{ }^{125} \mathrm{I}\right] \mathrm{IMPY}$ binding were obtained in cerebellar homogenates prepared from postmortem AD brains. ${ }^{(8)}$ The location and density of the specific signal detected by $\left.{ }^{[25} \mathrm{I}\right] \mathrm{IMPY}$ correlated with the distribution of amyloid plaques in brain specimens, as confirmed by thioflavin-S (TF-S) staining. ${ }^{(8)}$ Most importantly, $\left[{ }^{125} \mathrm{I}\right] \mathrm{IMPY}$ has been used as the standard radiotracer in competitive binding experiments for screening of potential plaque binding agents.

When molecular imaging for neurodegenerative disease, i.e. the $\mathrm{AD}$ project, was initiated at Chang Gung Memorial Hospital (CGMH) and Chang Gung University (CGU) in Taiwan in late 2007 , [ $\left.{ }^{125} \mathrm{I}\right] \mathrm{IMPY}$ was introduced as the first radiotracer targeting amyloid plaques. [125I]IMPY was successfully prepared at CGU with high specific activity of $2,200 \mathrm{Ci} / \mathrm{mmol}$ and greater than $95 \%$ radiochemical purity. In addition to laying the foundation for tracer preparation, the screening methodology using [ ${ }^{125}$ I]IMPY for in vitro plaque binding as well as brain section labeling (in vitro autoradiography) was established at CGU. The capability to perform these preclinical evaluations was essential for later followup screening and validation of newly introduced radiotracers.

\section{AV-138 Study}

For a decade, development of SPECT imaging tracers for amyloid plaques met with limited success. In contrast, positron emission tomography (PET) plaque imaging with PIB has demonstrated the feasibility of clearly visualizing plaques in living human brains. ${ }^{(12)}$ Plaque pathology can be detected not only in patients with $\mathrm{AD}$, but also those with mild cognition impairment (MCI) and even some control sub- 
jects who show positive pathology with PIB. ${ }^{(13)}$ However, the short half-life $(20 \mathrm{~min})$ of ${ }^{11} \mathrm{C}$ in PIB limits its usefulness for widespread clinical application. With the recent successful development of several PET plaque imaging agents labeled with ${ }^{18} \mathrm{~F}\left(\mathrm{t}_{1 / 2}\right.$ $=109 \mathrm{~min}){ }^{(14-18)}$ the urgent need to move on to new ${ }^{18} \mathrm{~F}$-labeled plaque imaging agents at $\mathrm{CGMH} / \mathrm{CGU}$ was immediately realized and work in this area proceeded. Under the sponsorship of a small biotech company, Avid Radiopharmaceuticals, Inc. ${ }^{(19)}$ several ${ }^{18} \mathrm{~F}$-labeled plaque imaging agents originally developed at the University of Pennsylvania ${ }^{(14,15)}$ were subsequently demonstrated to be potentially useful preclinically. Under an agreement with Avid, the first ${ }^{18} \mathrm{~F}$-labeled PET tracer targeting amyloid plaques, [4-((4-(2-(2-(2-fluoroethoxy)ethoxy)ethoxy)phenyl)ethynyl)- $N$-methylbenzenamine] (AV-138) was introduced at CGMH/CGU in early 2008.

$\mathrm{AV}-138$ belongs to a series of fluoropegylated diphenlacetylene derivatives based on a triple-bonded structure (Fig. 1). Consistent with data reported previously ${ }^{(20)}$ the high binding affinity of nonradioactive AV-138 with $K_{\mathrm{i}}$ values of $2.4 \pm 0.7 \mathrm{nM}$ was confirmed side by side with nonradioactive IMPY $\left(K_{\mathrm{i}}=4.0 \pm 2.5 \mathrm{nM}\right)$ for $\mathrm{A} \beta$ aggregates (Fig. 2). ${ }^{(21)}$

To ensure timely delivery of radiofluoro-labeled $\mathrm{AV}-138$ and to comply with the guidelines of PET tracer manufacturing for further clinical application, a one-step, one-pot radiofluorination approach was used. The Sumitomo automated modules at the cyclotron facility of CGMH were used for radiosyn-

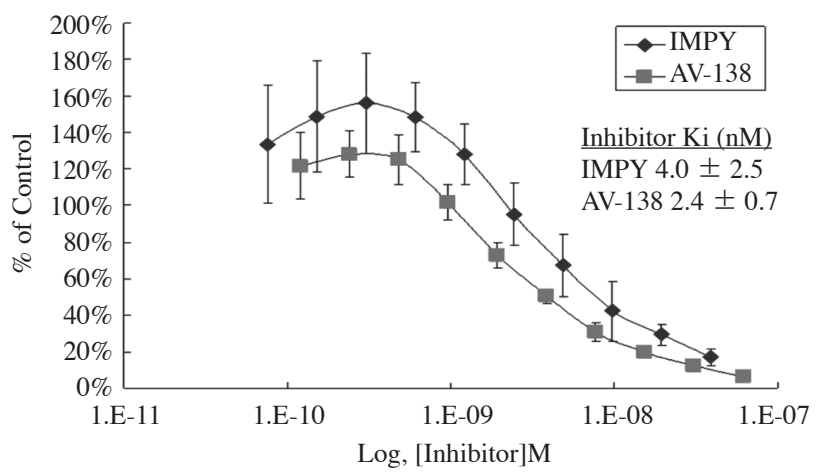

Fig. 2 Comparison of IMPY and AV-138 in [ $\left.{ }^{125}\right]$ IMPY binding in AD brain homogenates. AV-138 shows a binding affinity similar to IMPY with $K_{\mathrm{i}}$ values of $4.0 \pm 2.5$ and $2.4 \pm 0.7$ nM, for IMPY and AV-138, respectively. Each value was determined three times with a duplicate for each measurement. thesis following a method described previously with some modifications. ${ }^{(21)}$

As expected, specific binding of AV-138 was clearly observed mainly in $\mathrm{AD}$ gray homogenates (plaque-enriched region), with a low signal in $\mathrm{AD}$ white homogenates (minimal plaques present). The ratio between gray and white homogenates reached as high as 10 (Fig. 3). ${ }^{(21)}$ In contrast, there was very low binding signal present in both control gray and white homogenates. The huge binding signal difference between AD gray and control gray homogenates was related to the presence of significant amounts of measurable $A \beta$ plaques present in $\mathrm{AD}$ gray but not in control gray tissues. Thus, the phenylacetylene ligand $\mathrm{AV}-138$ is desirable, based on the higher $A \beta$ plaque signal and the lower nonspecific binding that are comparable to PIB and other ${ }^{18} \mathrm{~F}$ labeled tracers. ${ }^{(22)}$

Using a high-resolution FLA-5000 phosphor imager to replace traditional film autoradiography, excellent images (FujiFilm, Tokyo, Japan) of A $\beta$ plaque labeling with both [ $\left.{ }^{125} \mathrm{I}\right] \mathrm{IMPY}$ and $\mathrm{AV}-138$ could be detected (Fig. 4A). Fluorescence signals from plaques stained with TF-S on the brain sections could readily be visualized (Fig. 4B). A fused image

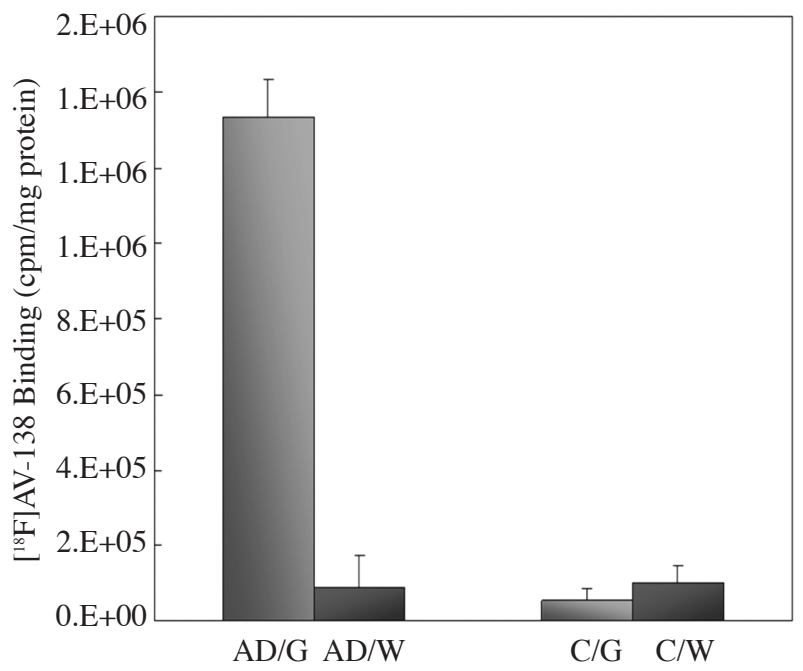

Fig. 3 Binding of $\mathrm{AV}-138$ to $\beta$-amyloid plaques in postmortem brain homogenates in pooled AD patients and controls. Specific binding can be clearly seen in the AD gray matter $(\mathrm{AD} / \mathrm{G})$ homogenates, but not in the $\mathrm{AD}$ white matter $(\mathrm{AD} / \mathrm{W})$ and control brain homogenates $(\mathrm{C} / \mathrm{G}$ and $\mathrm{C} / \mathrm{W})$. Data are expressed as mean $\pm \mathrm{SD}$ and are the average of three independent experiments with duplicate values for each measurement. 
shown in Fig. 4C confirmed the consistency and the match for these two different labels. ${ }^{(21)}$

During the radiofluorination of AV-138, we faced a low yield (3.3\%-8.5\%, decay corrected) and an unexpected sticking problem associated with this ${ }^{18} \mathrm{~F}$ tracer. Several attempts to improve the automation synthesis were not successful. Because this unfavorable property could ultimately decrease the widespread clinical application of the automated synthesis, we looked for other potential tracers as possible replacements.

\section{AV-45 Study}

With exploratory investigational new drug (IND) guidance (approved Jan, 2006 from the Food and Drug Administration in the United States) in effect, Avid quickly began human trials of more than a dozen potential ${ }^{18} \mathrm{~F}$ PET imaging agents which were selected based on various preclinical criteria targeting amyloid plaques. ${ }^{(19)} \mathrm{AV}-45,(E)-4-(2-(6-(2-$ (2-(2-fluoroethox yethoxy)ethoxy)pyridin-3yl)vinyl)- $N$-methyl benzenamine, and $\mathrm{AV}-138$ were among the final four tracers with the best pharmacokinetics and pharmacodynamics for imaging brain amyloid deposits in humans. AV-45, similar to AV138, is a fluoropegylated PET tracer (Fig. 1) with a double bond (instead of the triple bond in AV-138) connecting phenyl and pyridine rings (AV-138 has two phenyl rings instead). With this unique structure, AV-45 displayed relatively fast kinetics (brain uptake and background washout) resulting in the best imaging contrast (plaque signal vs. white matter background) less than one hour after tracer injection. ${ }^{(19)}$

Although successful automated synthesis of AV138 was readily achieved at CGMH, ${ }^{(21)}$ excellent imaging results were observed for $\mathrm{AV}-45,{ }^{(19,23,24)}$

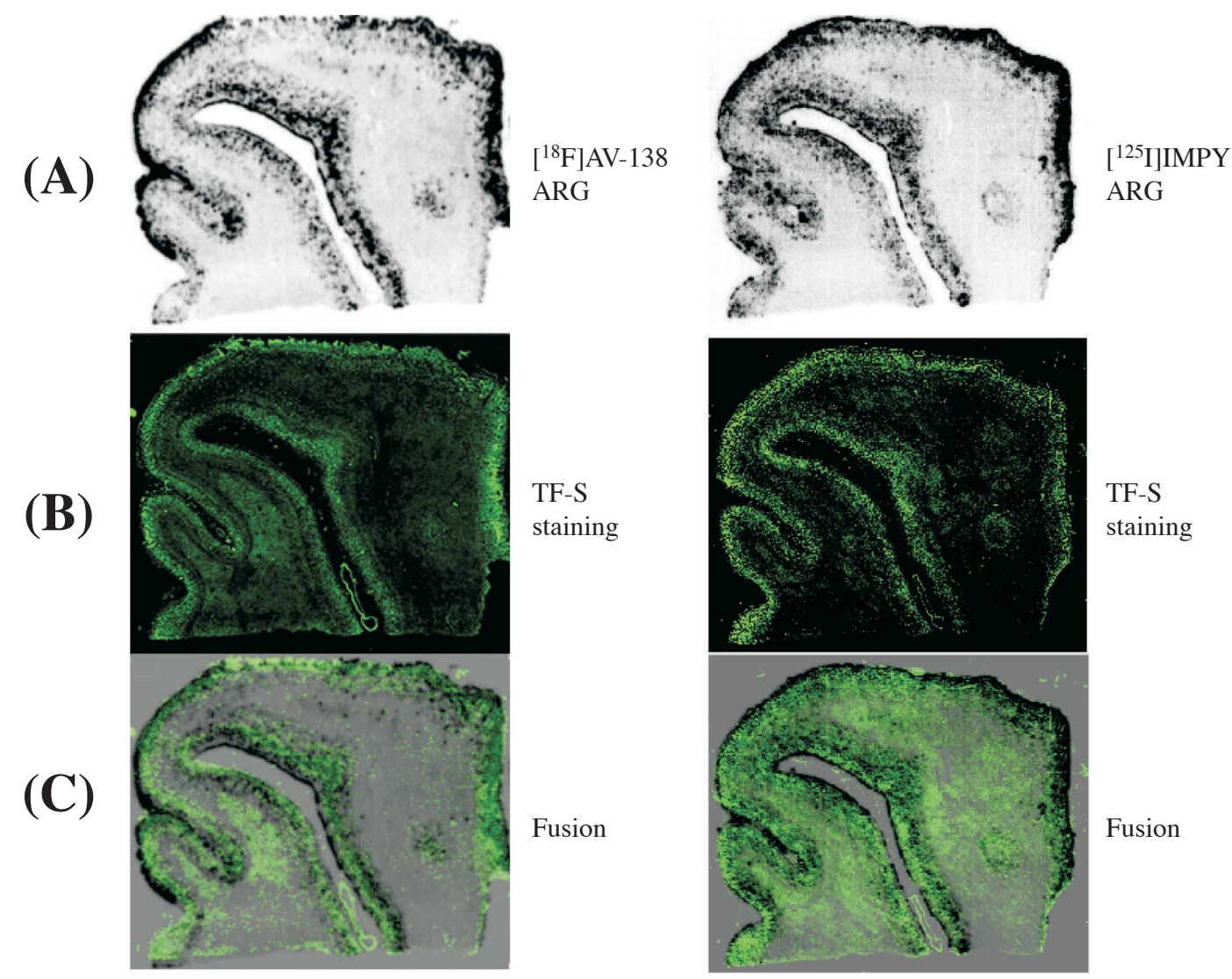

Fig. 4 In vitro autoradiography of postmortem AD brain sections with [125I]IMPY or AV-138. The same section was fluorescently stained with Th-S. Both nuclear and fluorescent images were analyzed and quantified with a high-resolution phosphor imager. (A) AV-138 or [ ${ }^{125}$ I]IMPY imaging; (B) Thioflavin-S (TF-S) staining; (C) Fusion imaging. 
which prompted us to quickly switch to this agent for future clinical studies. We chose to carry out more detailed evaluations for institutional production and validation of AV-45 for clinical imaging studies targeting $A \beta$ plaques. The goal of timely delivery of AV-45 for possible widespread clinical applications complying with the guidelines of PET tracer manufacturing was quickly achieved at CGMH.

The properties of the generated AV-45 under good manufacturing practice-compliant automated synthesis was further validated for specific $A \beta$ plaque binding. Saturated binding with high affinity $\left(K_{\mathrm{d}}=2.59 \mathrm{nM}\right)$ and high capacity $\left(B_{\max }=9,326\right.$ $\mathrm{fmol} / \mathrm{mg}$ protein) was observed in AD gray homogenates (Fig. 5). The binding signal was observed mainly in $\mathrm{AD}$ gray homogenates, with low signal in $\mathrm{AD}$ white homogenates (minimal plaques present) reaching a high contrast of 8 (data not shown).

With the production of the radiopharmaceutical $\mathrm{AV}-45$ in place, a phase I human study began at CGMH. The pilot study focused mainly on the in vivo biodistribution, safety, and radiation dosimetry of AV-45 in human subjects. PET AV-45 amyloid imaging was also performed in a group of patients with AD and healthy elderly controls without dementia.

AV-45 did not show any noticeable pharmacological effects in any of the subjects. High absorbed doses were found in the gallbladder wall, liver, and

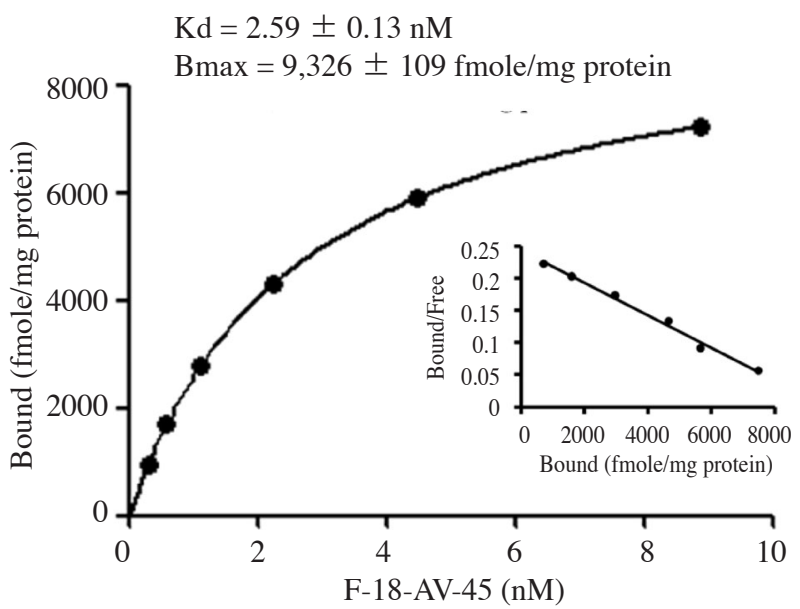

Fig. 5 Representative saturation and Scatchard plots of AV45 in AD gray homogenates showing high binding affinity and high capacity. upper large intestine wall.(.27) The critical organ was the gallbladder wall, which received $58.7 \mathrm{~Gy} / \mathrm{MBq}$. The effective dose equivalent and effective dose for $\mathrm{AV}-45$ were $23.37 \pm 2.54 \mathrm{~Sv} / \mathrm{MBq}$ and $16.87 \pm$ $0.60 \mathrm{~Sv} / \mathrm{MBq}$, respectively. ${ }^{(26)}$

PET brain imaging of AV-45 demonstrated that its localization in the frontal, parietal and precuneus cortex in AD patients but not in the brains of control patients was consistent with the pattern of amyloid distribution (Fig. 6). A high standardized uptake value ratio of the frontal cortex to the cerebellum was reached between 50-60 min after injection of the radiopharmaceutical.

The results of this pilot phase I study showed that AV-45 is a safe PET tracer for studying amyloid plaque distribution in the brain. The administration of $\mathrm{AV}-45$ leads to a reasonable radiation burden in investigated subjects which does not preclude longitudinal studies.

\section{Conclusion}

There has been rapid progress in the field of imaging for plaque pathology. AV-45 was the first
(A)

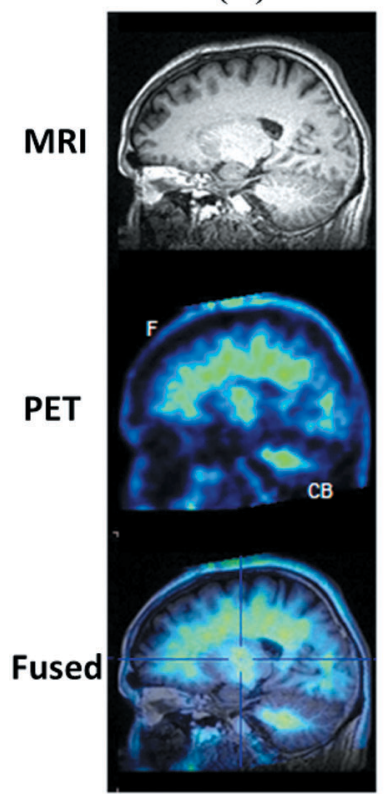

(B)

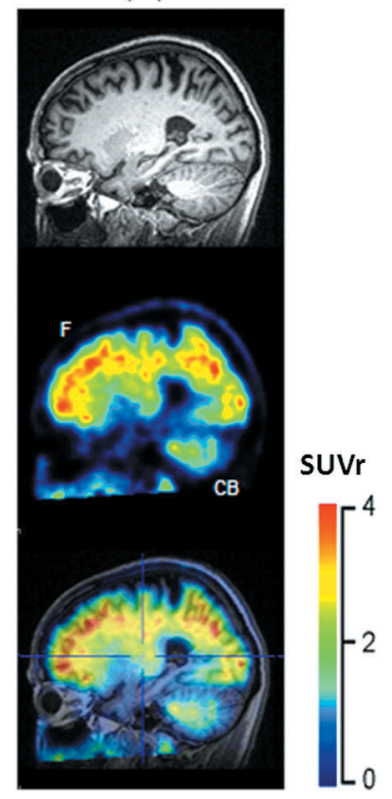

Fig. 6 AV-45 brain images of a healthy control (A), and AD patient (B) at time intervals of 50-60 min postinjection. The color scale was normalized to the cerebellum cortex for comparison. Abbreviations used: F: frontal cortex; CB: cerebellum. 
plaque imaging agent to enter multicenter, IND clinical trials in the US, and has now been studied in dozens of trials with more than 1,000 subjects ranging from cognitively normal individuals to those with AD dementia. "Imaging to autopsy" phase III studies further confirmed and validated the specific imaging signal correlated to the plaque burden in living subjects. With these promising and confirmed characteristics of AV-45, the Alzheimer's Disease Neuroimaging Initiative (ADNI) under common consensus decided on AV-45 as the standard PET imaging agent for evaluating the progression of plaque pathology in patients with AD or MCI, and even healthy controls. With the wide availability of AV-45 for plaque imaging, the ultimate goal of the ADNI is global clinical trials for disease detection and progression.

The production of the PET plaque tracer AV-45 in Taiwan, particularly in CGMH, is ready for clinical trials. Likely, there will be another site steadily producing AV-45 for distribution. With the joint efforts of neurologists and nuclear medicine physicians as well as radiochemists and medical physicists, a bright future using AV-45 for PET plaque imaging in Taiwan is expected.

\section{Acknowledgements}

The authors are indebted to Dr. Lee-Way Jin and the Alzheimer's Disease Center, University of California, Davis, CA, U.S.A., for providing human postmortem brain tissues. We thank Avid Radiopharmaceuticals, Inc. (Philadelphia, PA, U.S.A.) for providing the precursor for the preparation of $18 \mathrm{~F}-\mathrm{AV}-45$. This study was carried out with financial support from the National Science Council, Taiwan (NSC 99-2623-E-182-009-NU, NSC 992314-B-182-036-MY3 and NSC 99-2811-B-182006).

\section{REFERENCES}

1. Hardy J, Selkoe DJ. The amyloid hypothesis of Alzheimer's disease: progress and problems on the road to therapeutics. Science 2002;297:353-6.

2. Selkoe DJ. Imaging Alzheimer's amyloid. Nat Biotechnol 2000;18:823-4.

3. Thorsett ED, Latimer LH. Therapeutic approaches to Alzheimer's disease. Curr Opin Chem Biol 2000;4:37782.

4. Vickers JC, Dickson TC, Adlard PA, Saunders HL, King
CE, McCormack G. The cause of neuronal degeneration in alzheimer's disease. Prog Neurobiol 2000;60:139-65.

5. Dovey HF, John V, Anderson JP, Chen LZ, de Saint Andrieu P, Fang LY. Functional gamma-secretase inhibitors reduce beta-amyloid peptide levels in brain. $\mathrm{J}$ Neurochem 2001;76:173-81.

6. Schenk D, Barbour R, Dunn W, Gordon G, Grajeda H, Guido T, Hu K, Huang J, Johnson-Wood K, Khan K, Kholodenko D, Lee M, Liao Z, Lieberburg I, Motter R, Mutter L, Soriano F, Shopp G, Vasquez N, Vandevert C, Walker S, Wogulis M, Yednock T, Games D, Seubert P. Immunization with amyloid-b attenuates Alzheimer-disease-like pathology in the PDAPP mouse. Nature 1999;400:173-7.

7. Kung MP, Hou C, Zhuang ZP, Zhang B, Skovronsky D, Trojanowski JQ, Lee VM, Kung HF. IMPY: An improved thioflavin-T derivative for in vivo labeling of b-amyloid plaques. Brain Res 2002;956:202-10.

8. Kung MP, Hou C, Zhuang ZP, Skovronsky D, Kung HF. Binding of two potential imaging agents targeting amyloid plaques in postmortem brain tissues of patients with Alzheimer's disease. Brain Res 2004;1025:89-105.

9. Kung MP, Hou C, Zhuang ZP, Cross AJ, Maier DL, Kung HF. Characterization of IMPY as a potential imaging agent for beta-amyloid plaques in double transgenic PSAPP mice. Eur J Nucl Med Mol Imaging 2004;31: 1136-45.

10. Klunk WE, Lopresti BJ, Ikonomovic MD, Lefterov IM, Koldamova RP, Abrahamson EE, Debnath ML, Holt DP, Huang GF, Shao L, DeKosky ST, Price JC, Mathis CA. Binding of the positron emission tomography tracer Pittsburgh compound-B reflects the amount of amyloidbeta in Alzheimer's disease brain but not in transgenic mouse brain. J Neurosci 2005;25:10598-606.

11. Maeda J, Ji B, Irie T, Tomiyama T, Maruyama M, Okauchi T, Staufenbiel M, Iwata N, Ono M, Saido TC, Suzuki K, Mori H, Higuchi M, Suhara T. Longitudinal, quantitative assessment of amyloid, neuroinflammation, and anti-amyloid treatment in a living mouse model of Alzheimer's disease enabled by positron emission tomography. J Neurosci 2007;27:10957-68.

12. Klunk WE, Engler H, Nordberg A, Wang Y, Blomqvist G, Holt DP, Bergstrém M, Savitcheva I, Huang GF, Estrada S, Ausén B, Debnath ML, Barletta J, Price JC, Sandell J, Lopresti BJ, Wall A, Koivisto P, Antoni G, Mathis CA, Långström B. Imaging brain amyloid in Alzheimer's disease with Pittsburgh Compound-B. Ann Neurol 2004;55: 306-19.

13. Forsberg A, Engler H, Almkvist O, Blomquist G, Hagman G, Wall A, Ringheim A, Långström B, Nordberg A. PET imaging of amyloid deposition in patients with mild cognitive impairment. Neurobiol Aging 2008;29:1456-65.

14. Zhang W, Oya S, Kung MP, Hou C, Maier DL, Kung HF. F-18 stilbenes as PET imaging agents for detecting $\beta$ amyloid plaques in the brain. J Med Chem 2005;48:5980- 
8.

15. Zhang W, Oya S, Kung MP, Hou C, Maier DL, Kung HF. F-18 PEG stilbenes as PET imaging agents targeting A $\beta$ aggregates in the brain. Nucl Med Biol 2005;32:799-809.

16. Kudo Y, Okamura N, Furumoto S, Tashiro M, Furukawa K, Maruyama M, Itoh M, Iwata R, Yanai K, Arai H. 2-(2[2-Dimethylaminothiazol-5-yl]ethenyl)-6- (2-[fluoro] ethoxy) benzoxazole: a novel PET agent for in vivo detection of dense amyloid plaques in Alzheimer's disease patients. J Nucl Med 2007;48:553-61.

17. Koole M, Lewis DM, Buckley C, Nelissen N, Vandenbulcke M, Brooks DJ, Vandenberghe R, Van Laere $\mathrm{K}$. Whole-body biodistribution and radiation dosimetry of ${ }^{18} \mathrm{~F}-\mathrm{GE} 067$ : a radioligand for in vivo brain amyloid imaging. J Nucl Med 2009;50:818-22.

18. Nelissen N, Van Laere K, Thurfjell L, Owenius R, Vandenbulcke M, Koole M, Bormans G, Brooks DJ, Vandenberghe R. Phase 1 study of the Pittsburgh compound $\mathrm{B}$ derivative ${ }^{18} \mathrm{~F}$-flutemetamol in healthy volunteers and patients with probable Alzheimer disease. J Nucl Med 2009;50:1251-9.

19. Carpenter AP Jr, Pontecorvo MJ, Hefti FF, Skovronsky DM. The use of the exploratory IND in the evaluation and development of ${ }^{18} \mathrm{~F}$-PET radiopharmaceuticals for amyloid imaging in the brain: a review of one company's experience. Q J Nucl Med Mol Imaging 2009;53:387-93.

20. Chandra R, Oya S, Kung MP, Hou C, Jin LW, Kung HF. New diphenylacetylenes as probes for positron emission tomographic imaging of amyloid plaques. J Med Chem 2007;50:2415-23.

21. Wey SP, Weng CC, Lin KJ, Yao CH, Yen TC, Kung HF, Skovronsky D, Kung MP. Validation of an ${ }^{18} \mathrm{~F}$-labeled biphenylalkyne as a positron emission tomography imaging agent for $\beta$-amyloid plaques. Nucl Med Biol 2009;36:411-7.

22. Rowe CC, Ackerman U, Browne W, Mulligan R, Pike KL, O'Keefe G, Tochon-Danguy H, Chan G, Berlangieri SU, Jones G, Dickinson-Rowe KL, Kung HP, Zhang W, Kung MP, Skovronsky D, Dyrks T, Holl G, Krause S, Friebe M, Lehman L, Lindemann S, Dinkelborg LM, Masters CL, Villemagne VL. Imaging of amyloid $\beta$ in Alzheimer's disease with ${ }^{18} \mathrm{~F}-\mathrm{BAY} 94-9172$, a novel PET tracer: proof of mechanism. Lancet Neurol 2008;7:129 35.

23. Choi SR, Golding G, Zhuang Z, Zhang W, Lim N, Hefti F, Benedum TE, Kilbourn MR, Skovronsky D, Kung HF. Preclinical properties of ${ }^{18} \mathrm{~F}-\mathrm{AV}-45$ : a PET agent for $\mathrm{A} \beta$ plaques in the brain. J Nucl Med 2009;50:1887-94.

24. Skovronsky D, Coleman RE, Frey K, Garg P, Ichise M, Lowe V, Mintun M, Wong D, Kung H. Avid Amyloid Research Group. Results of multi-center clinical trials comparing four ${ }^{18} \mathrm{~F}$ PET amyloid-imaging agents: Preclinical to clinical correlations. J Nucl Med 2008;49:34p.

25. Yao CH, Lin KJ, Weng CC, Hsiao IT, Ting YS, Yen TC, Jan TR, Skovronsky D, Kung MP, Wey SP. GMP-compliant automated synthesis of $\left[{ }^{18} \mathrm{~F}\right] \mathrm{AV}-45$ (Florbetapir F 18) for imaging $\beta$-amyloid plaques in human brain. Appl Radiat Isot 2010;68:2293-7.

26. Lin KJ, Hsu WC, Hsiao IT Wey SP, Jin LW, Skovronsky D, Wai YY, Chang HP, Lo CW, Yao CH, Yen TC, Kung MP. Whole-body biodistribution and brain PET imaging with $\left[{ }^{18} \mathrm{~F}\right] \mathrm{AV}-45$, a novel amyloid imaging agent-a pilot study. Nucl Med Biol 2010;37:497-508. 


\title{
從 IMPY/SPECT 到 AV-45/PET 探索類澱粉䐉廐造影
}

\author{
田美萍 ${ }^{1,2}$ 翁啓昌 $^{3}$ 林昆儒 ${ }^{1,4}$ 蕭穎聰 $^{1}$ 閻紫宸 $^{4}$ 魏孝萍 $^{1}$
}

腦内乙型類澱疪塊的形成與沉積是阿爾茲海默氏病最早期的病理變異。針對乙型類澱 粉㾬塊的分子影像可以作爲阿爾茲海默氏病早期診断與神經病理機轉研究的一項替代指標。 迄今已有多種放射性標儎藥物被研發作爲以單光子放射電腦斷層掃描 (SPECT) 或正子放射斷 層掃描 (PET) 等非侵入方式檢測阿爾茲海默氏病患者腦内乙型類澱粉疰塊的造影劑。本文回顧 長庚大學與長庚紀念醫院近年探索乙型類澱粉廐塊核醫造影劑的經驗歷程。(長庚醫誌 2012;35:211-8)

關鍵詞：乙型類澱粉痽塊, 阿雨茲海默氏病, AV-45, AV-138, IMPY

1長庚大學 健康老化研究中心; 醫學影像暨放射科學系; 2美國賓州大學醫學院 放射醫學系; 3國立清華大學 生醫工程與 環境科學系；4長庚醫療財團法人林口長庚紀念醫院 核子醫學科 分子影像中心

受文日期：民國100年1月14日；接受刊載：民國100年11月30日

通訊作者：田美萍教授, 美國賓州大學醫學院 放射醫學系。1 Donner, Philadelphia, PA 19104, U.S.A. Tel: 001-484-2708175;

E-mail: kungmp@gmail.com 